\title{
Mechanisms of Scarless Repair at Time of Menstruation: Insights From Mouse Models
}

\author{
Phoebe M. Kirkwood, Isaac W. Shaw and Philippa T. K. Saunders* \\ Centre for Inflammation Research, The University of Edinburgh, Edinburgh, United Kingdom
}

The human endometrium is a remarkable tissue which may experience up to 400 cycles of hormone-driven proliferation, differentiation and breakdown during a woman's reproductive lifetime. During menstruation, when the luminal portion of tissue breaks down, it resembles a bloody wound with piecemeal shedding, exposure of underlying stroma and a strong inflammatory reaction. In the absence of pathology within a few days the integrity of the tissue is restored without formation of a scar and the endometrium is able to respond appropriately to subsequent endocrine signals in preparation for establishment of pregnancy if fertilization occurs. Understanding mechanisms regulating scarless repair of the endometrium is important both for design of therapies which can

OPEN ACCESS

Edited by:

Vargheese Chennathukuzhi, University of Kansas Medical Center, United States

Reviewed by: James Pru,

University of Wyoming, United States Gregory Burns,

Michigan State University United States

${ }^{*}$ Correspondence: Philippa T. K. Saunders p.saunders@ed.ac.uk

Specialty section: This article was submitted to Gynecology, a section of the journa Frontiers in Reproductive Health

Received: 25 October 2021 Accepted: 08 December 2021

Published: 06 January 2022

Citation:

Kirkwood PM, Shaw IW and Saunders PTK (2022) Mechanisms of

Scarless Repair at Time of Menstruation: Insights From Mouse Models.

Front. Reprod. Health 3:801843 doi: 10.3389/frph.2021.801843 treat conditions where this is aberrant (heavy menstrual bleeding, fibroids, endometriosis, Asherman's syndrome) as well as to provide new information that might allow us to reduce fibrosis and scar formation in other tissues. Menstruation only occurs naturally in species that exhibit spontaneous stromal cell decidualization during the fertile cycle such as primates (including women) and the Spiny mouse. To take advantage of genetic models and detailed time course analysis, mouse models of endometrial shedding/repair involving hormonal manipulation, artificial induction of decidualization and hormone withdrawal have been developed and refined. These models are useful in modeling dynamic changes across the time course of repair and have recapitulated key features of endometrial repair in women including local hypoxia and immune cell recruitment. In this review we will consider the evidence that scarless repair of endometrial tissue involves changes in stromal cell function including mesenchyme to epithelial transition, epithelial cell proliferation and multiple populations of immune cells. Processes contributing to endometrial fibrosis (Asherman's syndrome) as well as scarless repair of other tissues including skin and oral mucosa are compared to that of menstrual repair.

Keywords: hypoxia, endometrium, mesenchyme to epithelial transition (MET), inflammation, cytokine, angiogenesis, scarless

\section{INTRODUCTION}

The endometrium is unusual amongst adult tissue in that it exhibits an unparalleled capacity for rapid scar-free repair, which occurs at the end of each non-fertile cycle during the phase known as menstruation. Menstruation is the culmination of vascular, cellular and inflammatory changes which leaves the luminal surface in a "wounded" state (1). In order to limit blood loss and regain tissue function for the subsequent cycle, rapid re-epithelialisation and structural re-organization is 
required and occurs without the accumulation of any functional damage or fibrotic scar tissue (1-3). Although the human endometrium is the only adult tissue that undergoes regular and repeated cycles of destruction and repair under normal physiological conditions (4) parallels may be drawn between mechanisms of post menstrual endometrial repair and the wound healing response of the oral mucosa which also heals without a scar (5-7).

Whilst morphological and cellular changes that occur during the various phases of the human menstrual cycle have been well documented and extensively studied much less is known about the temporal and spatial changes in tissue function that occur during the menstrual phase due to the challenge of timing collection of human tissue during this phase (8). One of the most revealing studies to document the appearance of the endometrium at the time of menses used a combination of a hysteroscopic, histological and scanning electron microscopy. Examination of the surface of the endometrium during initial phases of menses revealed that tissue shedding and repair was not uniform but rather a "piecemeal process" which occurred simultaneously in regions throughout the uterine cavity with the authors suggesting the stromal compartment played an important role (9). One of the most well established mechanisms triggering tissue breakdown is the rapid fall in progesterone which occurs with involution of the corpus luteum in a non-fertile cycle (8). Progesterone also plays a pivotal role in stimulating changes in gene expression and cell function resulting in transformation of the stromal cells so that they secrete factors essential for successful implantation-a process collectively known as decidualization (10). During the normal cycle decidualization is limited to the luminal (functional) layer of the endometrium and this is also the region of tissue shed at menstruation. The occurrence of menstruation is associated with spontaneous decidualization, as opposed to decidualization induced by a fertilization event, and is limited to the higher-order primates including humans, four species of bat, the elephant shrew (11) and a Spiny mouse species (Acomys cahirinus $(12,13)$.

Studies in animal models have included those in primates that spontaneously menstruate such as the baboon (14) as well as species such as the macaque where menstruation can be induced by hormonal manipulation $(15,16)$. These models have been a valuable complement to studies on human tissue providing an opportunity to harvest samples that include the full thickness of the endometrium at defined timepoints during progesterone withdrawal to explore differences between gene expression in basal and functional zones (17). The classic studies undertaken by Markee (18) used rhesus tissue grafted into the ocular cavity allowing for direct observation of vasoconstriction in the spiral arteries. Notable results from primate studies have included timedependent expression of metalloproteinases in endometrium (15) (14) and endometrial grafts (19), studies on hypoxia and expression of angiogenic factors such as VEGF (20,21). Other models have included transplantation of human endometrial tissue into immunocompromised mice and in vitro culture of human tissue explants (16).

In addition to the clear intrinsic benefits of improved understanding of the mechanisms that regulate endometrial shedding and repair, this understanding is the basis for development of improved therapies for disorders such as heavy menstrual bleeding and endometriosis $(1,22)$. The endometrium may also serve as an exemplar of scarless repair with the potential to inform comparative studies and improve our understanding of chronic disease processes such as fibrosis.

\section{WHAT ARE THE ADVANTAGES AND BARRIERS TO USING MICE FOR STUDIES ON ENDOMETRIAL REPAIR?}

Whilst the uterus of rodents and women share a common architecture (luminal and glandular epithelial layers, complex stroma, myometrial muscle layers) the common, inbred species of laboratory mice and rats have relatively short "oestrus" cycles with four phases (proestrus, oestrus, met-oetrus, dioestrus) without spontaneous decidualization or cyclical tissue breakdown.

One of the incentives to develop and use mice in studies on endometrial function is the availability of a wide range of genetically modified animals including those using fluorescent protein to identify active promoters, to identify specific cell populations, and targeted deletion of genes either ubiquitously, in a cell-specific manner or following timed induction $(23,24)$. For example, in Pdgfrb-BAC-eGFP mice GFP is expressed under the control of the PDGFRbeta promoter (25) and a recent study has shown that the GFP is expressed in the cells of mesenchymal origin in the mouse endometrium mirroring the expression of the endogenous protein (26). Single cell gene expression analysis of $\mathrm{GFP}+$ cells recovered from cycling endometrium of $P d g f r b$-BACeGFP mice has identified five different populations of cells in the stroma including three transcriptionally distinct populations of fibroblast (26). Targeted deletion of the estrogen receptor alpha gene $(E s r 1)$ has been a powerful technique which when applied to studies on the mouse endometrium has provided novel insights into the importance of the stromal compartment in estrogen receptor dependent control of epithelial cell proliferation (27). Likewise our understanding of the pivotal role of progesterone in decidualization, fertility and regulation of downstream genes including those of the Wnt pathway has been illuminated by genetic manipulations involving the progesterone receptor gene (28).

\section{DEVELOPMENT AND REFINEMENT OF MOUSE MODELS OF ENDOMETRIAL REPAIR (MENSTRUATION)}

To overcome the critical limitation that mice lack a spontaneous decidualization response and provide a platform for improved understanding of the mechanisms regulating human menstruation mouse models based on hormonal manipulation have been developed: the most widely used involves ovariectomy of mice and was first reported by Finn and Pope in the 1980's (29), the second relies on induction of pseudopregnancy (30). 


\section{Ovariectomy Model of Endometrial Repair}

Briefly, adult female mice are ovariectomised, allowed to recover for 7 days to deplete endogenous hormones, primed with a hormone schedule to mimic the fluctuating hormones experienced by women during the menstrual cycle (estrogen priming and progesterone administration) and the endometrium artificially stimulated to induce decidualization, a process normally initiated following the arrival of a blastocyst in this species. A number of variations on this model have been reported but in all cases tissue breakdown was, as in women, triggered by cessation of progesterone stimulation (simulating CL demise).

In the original model reported in the 1980s 7 days after ovariectomy mice received daily injections of oestradiol (E2, 100 $\mathrm{ng} / 100 \mu \mathrm{l}, 2$ days); 3 days of rest, 3 days of injections of E2 (20 $\mathrm{ng} / 100 \mu \mathrm{l})$ and progesterone $(1 \mathrm{mg} / 100 \mu \mathrm{l})$ followed $4-6 \mathrm{~h}$ later by exposure of the uterus and intraluminal injection of peanut oil $(29,31)$. One problem with this model was variation in the extent of decidualization, however when it did occur removal of progesterone resulted in tissue breakdown accompanied by tissue necrosis, inflammation and luminal shedding (29). Notably the authors recorded changes in the stromal compartment which started with the congestion of dilated blood vessels followed by breakdown of the vessel walls and extravasation of blood. The basal area (outer ring) of the stroma proximal to the myometrium did not take part in the degenerative process but a central core of blood cells and degenerating decidual cells became detached and was shed into the lumen (29). Animals treated in exactly the same way but with the omission of the decidual stimulus did not show such changes in the stroma consistent with data from menstruating species which highlight the importance of stromal cell differentiation as a pre-requisite for the process of menstrual shedding (10).

The model was updated by the Salamonsen Group who modified the protocol to use inbred mice and to include a silastic progesterone-secreting pellet to replace progesterone injections thus ensuring a steadily increasing concentration of circulating progesterone, considered to be more comparable to what happens in women (32). Using this model decidualization was successfully induced in the uterine horns and endometrial breakdown was initiated $12-16 \mathrm{~h}$ following progesterone withdrawal. The entire decidua was detached and shed at $24 \mathrm{~h}$ and re-epithelialisation of the luminal surface was almost complete by 36 h. Notably this study was the first to define the endometrial breakdown and repair phase as being complete $48 \mathrm{~h}$ following withdrawal of progesterone (32). Wang and colleagues (33) investigated the critical time window for progesterone withdrawal using the Salmonsen group model with induction of decidualization by injection of acarchis oil into the lumen of one uterine horn on day 9 and removal of the pellet $49 \mathrm{~h}$ later. They reported that replacement of progesterone at 8 and $12 \mathrm{~h}$ after pellet removal blocked menstrual-like bleeding while replacement at $16-24 \mathrm{~h}$ had no effect and tissue shedding still occurred (33).

A further refinement to this model was reported by researchers in Edinburgh (Figure 1): specific changes included induction of decidualization by transvaginal injection of sesame oil directly into the uterine cavity thereby avoiding an additional abdominal surgery as well as an increase in the duration of progesterone administration (pellet in place) from 2 to 4 days after oil exposure ensuring a more robust and reproducible decidualization response (3, 34). In common with other reports shedding was maximal at $24 \mathrm{~h}$ after progesterone withdrawal, the luminal epithelial layer was typically intact at $48 \mathrm{~h}$ and tissue architecture resembled control intact mice by $72 \mathrm{~h}$. Overt vaginal bleeding was recorded.

Menning and colleagues also reported overt bleeding following induction of decidualization by injection of sesame oil into the uterus followed by removal of a P4 implant 4 days later (35): they recorded time dependent bleeding which was maximal at $24 \mathrm{~h}$ and used a tampon collection system to quantify the amount of blood providing a platform for testing drugs including those that modulate angiogenesis (35).

Peterse et al. (36) conducted a study to see if they could maximize the amount of decidual tissue that could be generated for use in a syngenetic model of endometriosis (37) they compared the response when the intrauterine oil stimulus was delivered via the vagina or via surgical laparotomy with the idea that the latter might be more "traumatic" to the tissue and therefore potentially elicit a more robust response (36). Decidualization was achieved in more than $83 \%$ of mice with significantly higher rates of bicornate decidualization in the laparotomic group (89\%) compared with vaginal administration (38\%) suggesting the former was useful if the priority of the study was to maximize decidual material but at the cost of extra surgical intervention.

\section{Pseudopregnancy Model}

Pseudopregnancy can be achieved by mating intact female mice to vasectomised males combined with artificial induction of decidualization. For example, Fan et al. mated adult female CD-1 mice with vasectomized males of the same strain combined with direct injection of $20 \mu \mathrm{l}$ sesame oil into each uterine lumen on day 4 of pseudopregnancy. On day 6 (2 days after oil injection), bilateral ovariectomy was performed to remove steroids and induce endometrial breakdown (30). When this pseudopregnancy model was used in combination with inhibition of Wnt7a endometrial repair was not normal with a failure of re-epithelialisation and degradation of the basal gland noted (38). In a modified version of the pseudopregnancy mouse model Rudolph et al administered the potent progesterone receptor antagonist mifepristone 2 days after induced decidualization instead of performing ovariectomy. This blockade mimicked progesterone withdrawal and stimulated decidual tissue breakdown. Bleeding was evaluated by vaginal lavage and was also visible at the opening of the vagina (39). Recently Wang et al used a pseudopregnancy model to investigate the impact of stress signals on menstrual breakdown (40) reporting that acute stress resulted in an increase in corticosterone contributing to more rapid breakdown and shedding of the endometrium.

In general the ovariectomy model is more widely used as it is very well established and usually considered to provide a more 


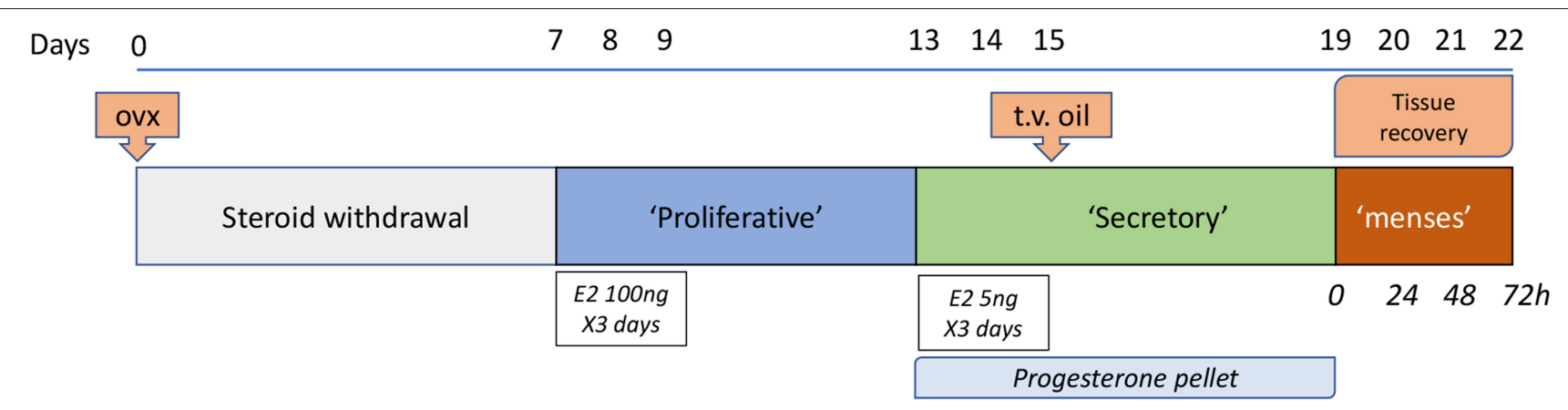

FIGURE 1 | Edinburgh Mouse model of menstruation. This model is based on the pioneering work of Finn and Pope (29) with several refinements including the use of a progesterone pellet (32) and induction of decidualization via a trans-vaginal [t.v.; (3)] route. Samples are recovered on day of pellet removal (time 0, full decidualization) and at times thereafter between 4 and $72 \mathrm{~h}$. Twenty four hours after pellet withdrawal has been characterized as a time of maximal tissue breakdown but by $48 \mathrm{~h}$ the epithelial layer surrounding the uterine lumen is typically fully restored.

reliable and reproducible timeframe for endometrial breakdown and repair.

\section{MECHANISMS IMPLICATED IN ENDOMETRIAL REPAIR IDENTIFIED IN MOUSE MODELS}

\section{Hormonal Regulation}

In women the menstrual phase of the cycle is characterized by low circulating concentrations of ovarian derived oestrogens and progesterone suggesting that endometrial repair processes are steroid independent. This question has also been addressed in the mouse models of menstruation. The standard ovx + mouse model of menstruation (Figure 1) is characterized by depletion of ovarian hormones with both shedding and repair occurring in the absence of endogenous oestrogens $(3,8)$. Kaitu'u-Lino and colleagues argued that other sources of oestrogens, including phytoestrogens in the diet and local metabolism in fat, might be available and the model could not be considered completely steroid-depleted (41). They therefore conducted the model using mice maintained on a soya-free diet and complementing this with administration of aromatase inhibitor letrozole (41). Importantly, no significant difference in the rate of endometrial repair was observed in the complete absence of estrogen, suggesting that this steroid was not essential for complete endometrial restoration in their model.

The presence of abundant androgen receptors in the stromal cells of the basal compartment, which remains intact during menses (42), and evidence for intracrine generation of bioactive androgens within endometrial tissue in response to decidualization (43) led Cousins et al to hypothesize that androgens could modulate the repair process even if the concentrations in blood were low (44). They administered a single injection of the potent bioactive, non-aromatizable androgen, dihydrotestosterone, in parallel with removal of the progesterone pellet. They reported that this treatment increased the duration of vaginal bleeding and delayed restoration of the luminal epithelium with striking spatial and temporal impacts on immunoexpression of MMPs 3 and 9 (44). These results may partially explain why women who have high androgen levels as a result of polycystic ovarian disease sometimes report heavy or extended bleeding during menses (45). Further investigation is required to pin down the precise role of androgens in the endometrial repair process.

\section{Hypoxia and Angiogensis}

Studies on human tissues and in primates have highlighted a role for hypoxia in regulation of endometrial repair processes and angiogenesis $(46,47)$. Withdrawal of progesterone is associated with an a marked increase in the synthesis of prostaglandins, increased arteriole vasoconstriction and a reduction in oxygen tension within the tissue (47). A key factor in sensing of oxygen tension in tissue is the transcription factor HIFla (hypoxia inducible factor one alpha) $(48,49)$. Stabilization of HIF1 $\alpha$ in human endometrial tissue has been detected during the secretory and menstrual phase and implicated in regulation of expression of genes involved in angiogenesis including IL8 $(46,50)$. In an in vitro model using human endometrial biopsies it has been shown that P4 withdrawal increased IL8 secretion but only in the presence of hypoxia (50). Coudyzer et al. published contrasting data from a xenograft model where fragments of human endometrium were engrafted to ovariectomised immunodeficient mice: in this model they could not detect evidence for increased HIF $1 \alpha$ and concluded that hypoxia is not required to trigger menstrual-like tissue breakdown or repair in human endometrium (51).

The results from studies in the mouse models of menstruation have demonstrated that hypoxia occurs following progesterone withdrawal and that this is also associated with levels of HIF1a and changes in expression of angiogenic genes. For example, Cousins et al. used hypoxyprobe ${ }^{\mathrm{TM}}$ to detect low oxygen levels and demonstrated dynamic changes in staining that were consistent with a striking increase in hypoxic conditions during the repair phase and time dependent changes in expression of angiogenesis-associated mRNAs encoded by Vegfa, Cxcl12, Flt1, and Kdr (34). These results have been complemented by investigations into the role of HIF which can have a dramatic impact on gene expression in low oxygen 
tissue environments (52). Notably using genetic targeting of Hif and pharmacological intervention in combination with the Edinburgh mouse model of endometrial repair Maybin and collaborators were able to manipulate the duration of endometrial shedding simulating heavy menstrual bleeding in women (52) with data supporting manipulation of HIF as a therapeutic target for this prevalent disorder.

The importance of angiogenesis was also confirmed by Menning et al (35) who administered Cediranib, a potent VEGF receptor signaling inhibitor, to mice on days 8 to 15 of their protocol (from day of decidualization to pellet removal) showing a drastic $85 \%$ reduction in menstrual like bleeding in treated animals compared with controls.

\section{Inflammation}

The human endometrium hosts a diverse population of immune cells, the abundance and composition of which changes throughout the menstrual cycle. Menstruation has been classified as an inflammatory event because the mechanisms and cellular changes involved are similar to those observed during other physiological inflammatory responses including the increase in the expression of prostaglandins, cytokines and chemokines which are secreted by the decidual cells in response to progesterone withdrawal $(50,53-55)$. The production of these factors is believed to stimulate the influx of inflammatory cells such as neutrophils and macrophage/monocyte populations (56, 57). Notably induction of excess inflammation in model systems has been shown to be associated with dysregulated repair and fibrosis (58) and may underlie some endometrial pathologies including heavy menstrual bleeding (8). Studies using the mouse models of menstruation have facilitated detailed time-dependent and spatial analysis of the inflammatory process and how it relates to both initiation and resolution of the endometrial menstrual "wound" with some of them highlighted below. In the 1980's Finn and Pope reported that one of the first changes in the decidualized mouse endometrium following cessation of progesterone was infiltration of leukocytes into the stroma (31). Subsequent studies have used a wide variety of methods to study the inflammatory response including immunohistochemistry and flow cytometry $(3,35,56)$, GFP-labeling of monocyte lineages (23) as well as antibody-dependent cell depletion (59). For example, in their 2003 paper Brasted et al (32) used an antibody directed against CD45 (leukocyte common antigen) to interrogate uterine tissue recovered $0,12,16,20,24,36$ and $48 \mathrm{~h}$ after removal of the progesterone pellet ( $\mathrm{P}$ withdrawal). Their analysis identified leukocytes in decidualized tissue often in close association with the luminal epithelium, throughout the basal zone and close to the newly regenerated epithelium at later time points. Notably they identified some of these cells as macrophages based on their morphology (32). Manning and colleagues used flow cytometry to analyse tissue digests recovered at 0,24 and $72 \mathrm{~h}$ time points. They reported a massive increase in of CD45+ cells so that they comprised $\sim 10 \%$ of the decidua at time zero (mostly NK cells, macrophages and granulocytes) with a striking increase in granulocytes (Gr1+/F480) making up 90\% of immune cells during maximal tissue shedding ( $24 \mathrm{~h})$. Armstrong et al compared tissue sections from human and mouse stained

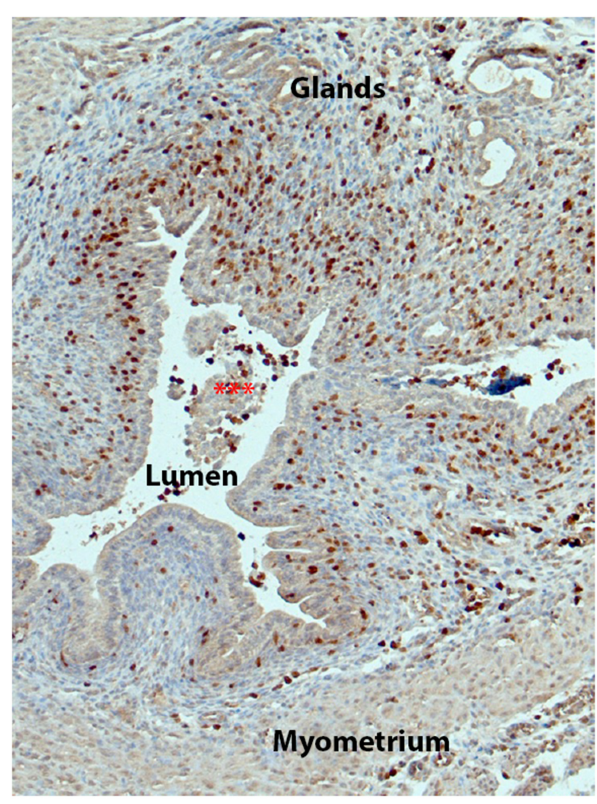

FIGURE 2 | Immune cells of the monocyte/macrophage lineage increase in the mouse endometrium during tissue breakdown. Figure shows endometrium from a Macgreen mouse $24 \mathrm{~h}$ after progesterone withdrawal with immune cells identified by immunostaining of GFP (brown, fluorescent images of similar tissues are shown in (23)). Note that there are abundant GFP+ cells in the stromal compartment with many adjacent to the newly intact luminal epithelium.

with antibodies directed against neutrophil elastase or GR1 respectively to focus on the neutrophil subtype of granulocytes demonstrating they increased at 8 hours after progesterone withdrawal and at $24 \mathrm{~h}(56)$ mimicking results in women and in agreement with other data from ovx models $(23,35,56)$. Cousins et al used transgenic "Macgreen" mice in which enhanced green fluorescent protein (EGFP) is expressed under the control of the c-fms promoter (encodes CSF-1R) expressed in the monocyte phagocytic lineage in the mouse (60) as well as some neutrophilic granulocytes (60). Using this lineage marker they were able to shed new light on the dynamic changes in monocyte derived immune cells over the course of tissue breakdown and repair [Figure 2 (23)]. One of the main findings from their study was that distinct populations of "classical" monocytes $(\mathrm{GFP}+\mathrm{F} 4 / 80-)$, monocyte-derived macrophages (GFP+F4/80+) and a population of putative tissue-resident macrophages (GFP$\mathrm{F} 4 / 80+$ ) that became localized to different regions within the tissue during breakdown, repair and remodeling suggesting cells of the monocyte lineage may play distinct roles in these processes (23). The recent application of single cell sequencing analysis of human endometrial tissue is likely to complement these findings by identifying immune cell subpopulations although datasets have not had sufficient depth of read to enable this (61).

The role(s) of immune cell populations have also been investigated using antibody depletion. For example, using the anti-mouse GR-1 antibody Menning and colleagues reported that cells positive for this marker (assumed to be neutrophils) played 
a role in regulating the expression of matrix modifying enzymes such as MMP3, 9 and 10 and their depletion impaired tissue repair (35). In another study cells were depleted using the antiGR1 (clone RB6-8C5) antibody and a delay in endometrial repair reported that was concluded to be a consequence of neutrophil depletion (59). The anti-GR1 (clone RB6-8C5) antibody binds to both Ly6G expressed solely on neutrophils and Ly6C expressed on neutrophils, monocytes and subsets of CD8 T cells (62) and therefore cannot be considered to be specific to one of these cell types. Notably Cousins et al (23) used the same RB6-8C 5 clone in their studies and reported that many of the GFP+(Ly6G-) monocytes they detected were also GR1+ hence depletion with this antibody is likely to target cells in addition to neutrophils and the immunostaining performed by Armstrong may need to be reevaluated (56).

In women there are well-documented increases in inflammatory chemokines and cytokines that coincide with the withdrawal of progesterone including CCL2 (MCP-1), CXCL8 (IL-8), IL-6, TNF, and COX-2 all showing increased expression in the late secretory and menstrual phases of the menstrual cycle (reviewed in (8)). Complementary studies in the mouse models have extended these findings. For example, Menning et al highlighted the very rapid and transient increase in expression of Cxcl2, Ccl3, Tnf, Il6 and Ccl2 (35). Other studies reported similar findings for Ccl2, Il6 and Cxcl8 (56).

Increased prostaglandin biosynthesis is also an important regulator of inflammatory processes during menstruation (8) that has been explored in the mouse "menstrual" models. In mice as in women induction of a menstrual like event is associated with increased expression of COX-2, an inducible enzyme that acts as a key regulator of the biosynthesis of prostaglandins from arachidonic acid $(35,63)$. Xu and colleagues used the mouse ovx model to demonstrate that administration of either a nonspecific COX inhibitor (indomethacin) or the COX-2 selective inhibitor DuP-697 led to less influx of leukocytes and inhibition of the menstrual-like process (63).

\section{Tissue Breakdown}

Studies in human tissue have highlighted a critical role for enzymes including matrix metalloproteinases in the destruction of the extracellular matrix (ECM) which is an essential step in tissue breakdown and shedding $(64,65)$. Historically, elegant studies in rhesus monkeys demonstrated a rapid rise in MMPs (stromelysins/matrilysin; MMP7, MMP3, MMP10) in the luminal portion of the endometrium in response to progesterone withdrawal (19).

Using their mouse model Kaitu'u-Lino et al examined the distribution of MMPs revealing an important role for MMP7 and MMP9 during endometrial tissue breakdown, and MMP3 and MMP7 during re-epithelialisation (66). However treatment of mice with the MMP inhibitors doxycycline and batimistat, both of which effectively reduced MMP activity, did not appear to have significant effects on endometrial breakdown or repair (66). The mouse model has been further used to demonstrate dynamic expression and functional importance of ECM interactions (67) and the expression of activin A in specific epithelial and stromal cell populations which may have a role in regulating re-epithelialisation (68). In their 2012 paper Menning et al documented dynamic time-dependent changes in mRNAs encoding Mmp1, 2, 3, 7, 9, 10, and 11. Cousins et al identified changes in the spatial and temporal expression of both MMP9 and MMP3 during the breakdown and repair phases $(3,12)$ which appeared consistent with the influx of immune cells known to produce MMPs highlighting the ability of the models to recapitulate changes seen in human tissue.

\section{Epithelial Migration and Proliferation}

Kaitu'u-Lino et al also used the mouse model to explore the role(s) of epithelial proliferation and progenitor cells in endometrial repair $(69,70)$. In one study newborn mouse pups were pulse-labeled with bromodeoxyuridine (BrdU) and chased for 5 week before decidualization, endometrial breakdown, and repair were induced (70). In the second study adult mice were also pulse labeled with BrdU immediately after induction of the same model. They reported that very rapid dilution of bromodeoxyuridine label was observed in the luminal epithelium consistent with rapid proliferation, whereas label within the glandular epithelium remained constant. In contrast during the later repair phase glandular epithelial cells had a decrease in detectable BrdU. The authors concluded that a population of epithelial progenitor cells may reside in the basal glands and contribute to postmenstrual repair (69).

In the studies by Cousins et al. they also reported rapid proliferation of epithelial cells including those remaining at the un-denuded surface of the luminal epithelium as well as some stromal cells and epithelial cells surrounding glands (3). In the conclusion of their paper they suggested that re-epithelialisation involves epithelial cell proliferation, epithelial cell migration and transformation of a subpopulation of stromal cells into those with epithelial characteristics in areas where the surface was denuded of epithelial cells (3). These studies provide new ideas about the mechanisms that might operate in parallel to ensure rapid repair of the luminal epithelial cell layer but require further interrogation and testing.

\section{Mesenchyme to Epithelial Transition (MET)}

One of the most striking features of endometrial shedding in women is the piecemeal loss of epithelium resulting in areas of denuded stroma (9). In mice the shedding of the decidual mass is not as piecemeal but it does result in areas of denuded stroma and it was in this region of the endometrium that Cousins and colleagues detected stromal cells which coexpressed vimentin and cytokeratin during the most active phase of endometrial repair ( $24 \mathrm{~h}$ after progesterone withdrawal) (3). These authors also analyzed the expression of genes implicated in mesenchymal-to-epithelial transition across the time course of the repair process with evidence of changes in expression of regulatory genes including $W t 1$ and members of the snail/slug family that are known to play a role in regulation of MET (3). Whether this is a transient change in the stromal population or is part of their differentiation into a functioning epithelium required further investigation.

Studies on postpartum endometrial repair have also provided evidence that MET occurs $(71,72)$. Specifically, the authors used 


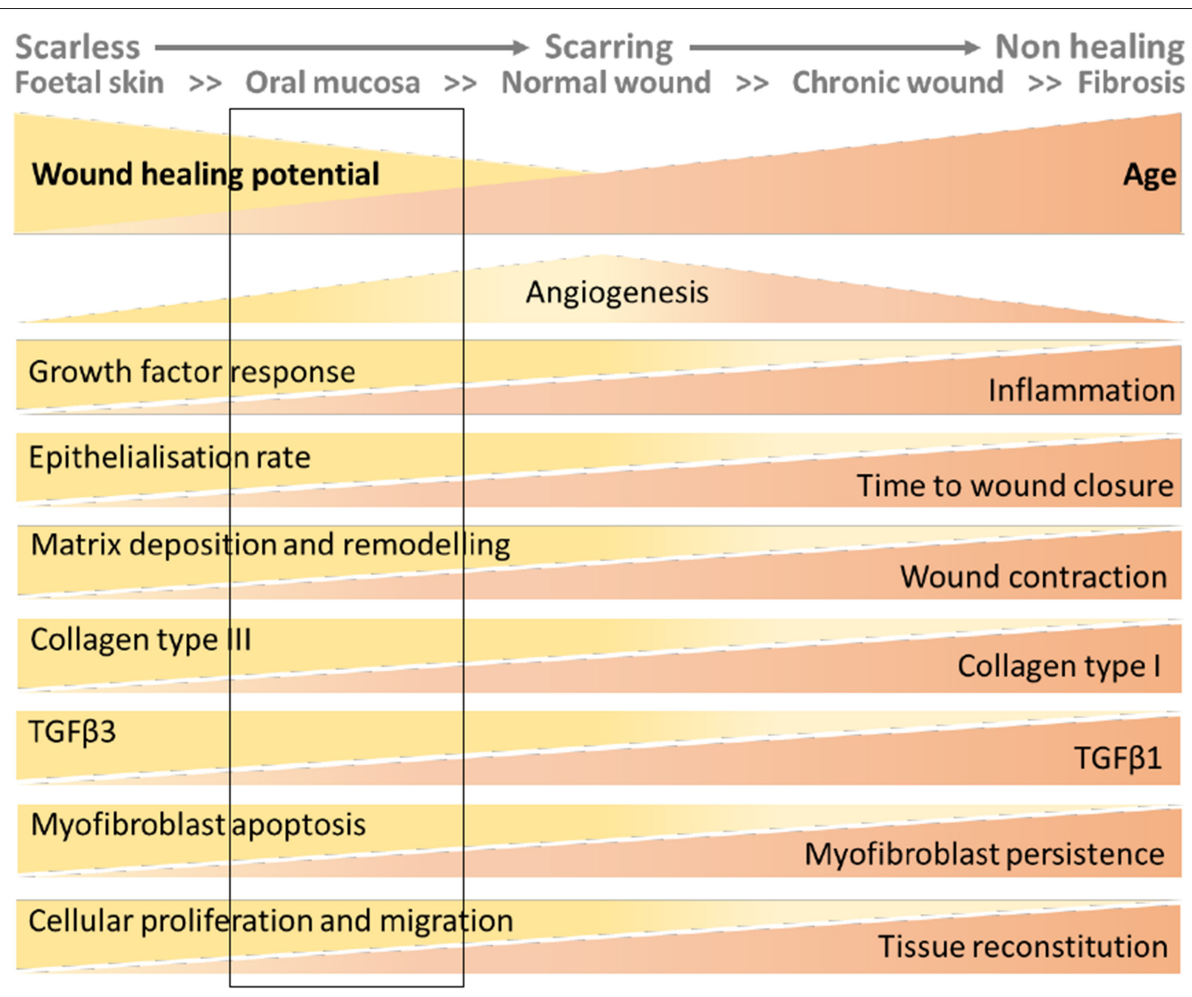

FIGURE 3 | Wound healing continuum with inclusion of putative location of endometrial tissue based on data from the mouse models. The figure has been adapted from that published in (100). The rectangular box added to the figure represents the characteristics of endometrial wound repair based on the interrogation of the mouse models described in this review.

genetic manipulation to allow for fate mapping of uterine cells expressing Amhr 2 using beta-galactosidase (71) or EGFP (72). In both studies positive signal (blue/EGFP) was restricted to stromal cells and myometrium in normal cycling mice but following parturition when there is extensive damage to the endometrial tissue, some of the labeled cells transformed into cells with epithelial characteristics, including expression of cytokeratin, and became incorporated into the luminal and glandular epithelial cell layers (71). In their 2013 study Patterson et al also used the mice in combination with the pseudopregnancy menses model described above and reported co-localization of vimentin (stromal marker) and cytokeratin (epithelial marker) in cells within the basal zone close to the myometrial border that peaked at $48 \mathrm{~h}$ post-ovx (72). Despite the location of these putative MET cells being different to that reported by Cousins (3) likely reflecting differences between the two models, these data further support a role for MET in post-menstrual repair.

A recent paper by Ghosh et al. (73) challenged the idea that MET was involved in maintenance and regeneration of the epithelium of the endometrium and oviduct. Specifically, they conducted a comprehensive examination of embryonic and adult reproductive tracts using LacZ reporter lines driven by promoters for Amhr2, Sm22, Cspg4, Thy1, and Pdgfr $\beta$ to explore whether epithelial cells expressing reporter protein arose in adulthood from MET or had an embryonic origin because they were induced at a time when cells had meso-epithelial characteristics.
In all cases they attributed epithelial expression of the reporter protein in adulthood to activation of the promoters during embryonic life ruling out MET in adult cycling mice (73).

Some of the findings summarized above are consistent with endometrial stromal cells having an inherent "plasticity" to change their phenotype from that of mesenchyme to one more consistent with epithelium. In addition to the studies on the menstrual models it is notable that decidualization might be considered as a form of hormone-induced MET with endometrial stromal fibroblasts acquiring epithelioid characteristics, such as expanded cytoplasm, rough endoplasmic reticulum, and a reorganized actin cytoskeleton (30). We postulate that this feature of endometrial mesenchymal cells may be an important contributor to the resilience of the endometrium to acute insults such as the breakdown and shedding of endometrium at the end of each menstrual cycle but further studies including those using lineage tracing are required to confirm this.

\section{Progenitor/Stem Cells}

Cells with stem cell-like properties, such as high proliferative potential, multilineage differentiation ability in vitro (adipo-, osteo- and myo-genic), and expression of stem cell-associated markers, have been identified in the human endometrium [basal compartment, perivascular location, PDGFR $\beta+C D 146+$, SUSD2+; $(74,75)]$, but the precise contribution of these cells to cyclical endometrial repair mechanisms remains the 
subject of intense investigation. Recent progress has included use of specific surface markers for isolation of progenitor/stem populations from tissue samples and menstrual effluent with novel applications proposed for regenerative medicine and tissue repair $(76,77)$. The role of stem/progenitor cells has also been investigated in the mouse model of menstruation although this has been challenging due to the lack of a specific lineage marker. A study by Kaitu'u-Lino et al using the LRC technique reported results suggesting that a population of epithelial progenitor cells might reside in the basal glands and that stromal LRC, located in a perivascular location could have an active role to play in endometrial repair (70). Despite evidence for the presence of multiple lineage-restricted stem/progenitor cell populations within the human/mouse uterus, the exact contribution to endometrial tissue repair remains elusive in part due to a lack of definitive markers. A recent study by Kirkwood et al identified an equivalent population of perivascular PDGFR $\beta+$ CD $146+$ cells in the mouse endometrium and demonstrated exclusive expression of NG2 (Cspg4) (26). The emergence of such novel identification markers will allow for their specific role in endometrial repair and regeneration to be interrogated.

\section{CAN WE TRANSLATE KNOWLEDGE GAINED FROM STUDIES ON ENDOMETRIAL REPAIR TO TREAT ENDOMETRIAL FIBROSIS?}

Endometrium repair is not always scar-free and intrauterine adhesions can occur as a result of a fibrotic response within the basal layer and is associated with poor pregnancy outcomes (78). The existence of these intrauterine adhesions is usually referred to as "Asherman's syndrome" (AS) with risk reported to be increased by repeated miscarriage, cesarean section and surgical removal of uterine contents [curatage; (79)]. Mouse models of AS have been developed by inducing a fibrotic response within the uterus by repeated "wounding" with a needle $(80,81)$. These models have been used to the test the ability of cell-based therapies to improve fertility, the rationale being that stem/progenitor cells may be involved in endometrial regeneration (82) and have been successfully applied for tissue repair in models of prolapse (77). One paper reported the use of human perivascular stem cells (hPVSCs) from umbilical cords was able to rescue the poor pregnancy outcome in AS mice via HIF1-dependent angiogenesis (83). Other studies have used mesenchyme cells derived from cultured human pluripotent stem cells (81) or from bone-marrow derived stem cells also with some promising results (84). A recent review considered a wider range of different sources of mesenchyme stem/stromal cells including menstrual blood [as discussed above, (76)] as well as evidence that extracellular vesicles secreted by these cells might also be considered as a cell free therapy for AS (85) which, given the logistical challenges of cell therapy, deserves further investigation.

Recently the importance of inflammatory pathways in the etiology of AS has gained more prominence (86) and this would be in agreement with their central role in endometrial repair (discussed above) as well as in the development of fibrosis in other tissues such as the liver (87). In a recent study immunostaining of endometrial tissue from 10 patients with AS identified not only increased amounts of fibrosis within the stromal compartment (collagen fibers and smooth muscle actin) but also alterations in macrophage phenotype (88). Changes in macrophage phenotype and pro-fibrotic cell changes are have also been identified in a mouse model of endometriosis (89), and in both disorders there appears to be potential for targeting macrophage phenotype/function as a novel therapy. Further insights from the mouse models of menstruation and comparison to those of AS may help refine the type(s) of immune and cell based therapies that can treat patients and improve their fertility.

\section{COMPARISONS BETWEEN MECHANISMS OF TISSUE REPAIR IN THE ENDOMETRIUM, FETAL SKIN AND ORAL MUCOSA}

Unchecked inflammation, fibrosis and scaring in response to tissue injury can result in significant tissue damage and associated morbidity (90). A number of studies have contributed to a greater understanding of the plasticity and heterogeneity of fibroblasts and their role in fibrosis (90). Whilst to date there has been little cross-over between studies using single cell analysis methods to explore fibroblast heterogeneity in fibrosis-prone tissues (90) and those using similar methods to interrogate endometrium in human (91) or mouse (26) this is clearly a topic that could be explored using existing data and bioinformatics to see if any of the endometrial cell subtypes have unique gene signatures. As the new single cell datasets have only recently been generated to date most attention has been paid to considering mechanisms that might explain scar-free healing of skin in the fetus and $(92,93)$ and lining of the mouth $(94,95)$ with a strong focus on exploring mechanisms that might be manipulated therapeutically in other sites (96).

A recent review summarized information obtained from studies using mice which have identified significant differences between gene expression in fibroblasts, deposition of extracellular matrix, the numbers of immune cells, expression of inflammatory regulators (IL33, prostaglandins) and metalloproteinases (MMPs) in fetuses where skin repair is rapid and scar-free (E15) and when scars are formed (E18/19) (93). In a detailed study using single cell fate mapping and 3D confocal imaging Jiang and colleagues identified two different fibroblast lineages that are responsible for the transition from scarless to skin scaring, again highlighting the importance of this cell type (92). Consistent with the results reported in fetuses repair of the oral mucosa also heals more rapidly than adult skin. In a recent study using nude mice, fibroblasts from the oral mucosa were shown to improve healing rates of adult skin wounds (97).

The inflammatory component of wound healing in the oral mucosa is associated with lower numbers of immune cells including macrophages, when compared to wounds of equivalent size in the adult skin, as well as decreased expression of the proinflammatory cytokines IL-6 and TGF $\beta 1$ (98). An animal model 
that can augment our understanding of skin repair is the African Spiny mice (Acomys) where cutaneous repair in adults closely resembles that of fetal stages of laboratory mice. Notably in this species skin repair is also associated with less inflammation, reduced collagen secretion and reduced numbers of macrophages mirroring findings in fetal mice (99). These results appear at odds with the wound response of the endometrium in which progesterone withdrawal triggers increased expression of inflammatory cytokines as well as a rapid increase in the numbers of immune cells including macrophages (8) but this may reflect the difference in the time scale and tissue response involved with endometrium breaking down and shedding over days whereas studies on skin wounding have focused on acute, usually incisional insults. Further comparisons between the inflammatory responses in skin and endometrium will be useful in finding both similarities and differences.

In summary, endometrium, fetal skin and oral mucosa all heal more rapidly than adult skin. Fibroblasts play a key role in regulating the efficiency of the repair processes in all these tissues. If we represent wounding of the skin as a continuum from scar-free in the fetus to the non-resolving wounds associated with aging (100) the endometrium would appear to most closely align with that of oral mucosa with rapid repair but potential for fibrosis (Figure 3).

\section{SUMMARY AND CONCLUSIONS}

The endometrium is a remarkable tissue which may experience 400 cycles of repeated breakdown, shedding and repair during a woman's lifetime with restoration of tissue architecture so that it is able regenerate and transform into a receptive state to receive the blastocyst during the next menstrual cycle. Endometrial repair is tightly regulated both temporally and spatially and maladaptations to the mechanisms responsible result in disorders including heavy menstrual bleeding (inefficient repair?) and Asherman's syndrome (intrauterine fibrosis/excess repair?) $(1,8)$.

\section{REFERENCES}

1. Maybin JA, Critchley HO. Menstrual physiology: implications for endometrial pathology and beyond. Hum Reprod Update. (2015) 21:748-61. doi: 10.1093/humupd/dmv038

2. Salamonsen LA. Review Tissue injury and repair in the female human reproductive tract. Reproduction. (2003) 125:301311. doi: 10.1530/rep.0.1250301

3. Cousins FL, Murray A, Esnal A, Gibson DA, Critchley HO, Saunders PT. Evidence from a mouse model that epithelial cell migration and mesenchymal-epithelial transition contribute to rapid restoration of uterine tissue integrity during menstruation. PLoS ONE. (2014) 9:e86378. doi: 10.1371/journal.pone.0086378

4. Gargett CE, Masuda H. Adult stem cells in the endometrium. Mol Hum Reprod. (2010) 16:818-34. doi: 10.1093/molehr/gaq061

5. Shaw TJ, Martin P. Wound repair at a glance. J Cell Sci. (2009) 122:320913. doi: $10.1242 /$ jcs. 031187

6. Leavitt T, Hu MS, Marshall CD, Barnes LA, Lorenz HP, Longaker MT. Scarless wound healing: finding the right cells and signals. Cell Tissue Res. (2016) 365:483-93. doi: 10.1007/s00441-016-2424-8
Whilst the common laboratory species of mouse do not naturally experience menstrual cycles protocols based on manipulation of hormones, artificial induction of stromal cell decidualization, and acute withdrawal of progesterone have led to the development of robust and reproducible induction of a "menses-like" event in the mouse endometrium. Comparison with human tissue samples shows that these models recapitulate the key physiological changes associated with menstruation. Specifically local/focal hypoxia, spatial and temporal expression of metalloproteinases, increased expression of angiogenic factors and inflammatory mediators, epithelial cell proliferation and the influx of large numbers of immune cells. An intact luminal epithelial layer is rapidly restored and the tissue appears "unwounded" within 48$72 \mathrm{~h}$ of progesterone withdrawal. Studies in mice have provided the platform for testing drugs and cell depletion to better inform new therapeutic opportunities for women's health disorders.

It is anticipated that further studies on the mouse models of menstruation, including more extensive comparison to regeneration and repair mechanisms in other tissues will continue to inform both our understanding of the normal physiology of menstruation but also an important platform for development of new therapies to treat conditions such as heavy menstrual bleeding, endometriosis and Asherman's syndrome.

\section{AUTHOR CONTRIBUTIONS}

All authors listed have made a substantial, direct, and intellectual contribution to the work and approved it for publication.

\section{FUNDING}

The University of Edinburgh provides funding to cover costs of open access publishing. Research in the author's group on endometrial biology has been supported by MRC MR/N024524/1.
7. Critchley HO, Kelly RW, Baird DT, Brenner RM. Regulation of human endometrial function: mechanisms relevant to uterine bleeding. Reprod Biol Endocrinol. (2006) 1:S5. doi: 10.1186/1477-7827-4-S1-S5

8. Critchley HOD, Maybin JA, Armstrong GM, Williams ARW. Physiology of the endometrium and regulation of menstruation. Physiol Rev. (2020) 100:1149-79. doi: 10.1152/physrev.00031.2019

9. Garry R, Hart R, Karthigasu KA, Burke C, A. re-appraisal of the morphological changes within the endometrium during menstruation: a hysteroscopic, histological and scanning electron microscopic study. Hum Reprod. (2009) 24:1393-401. doi: 10.1093/humrep/dep036

10. Gellersen B, Brosens JJ. Cyclic decidualization of the human endometrium in reproductive health and failure. Endocr Rev. (2014) 35:851-905. doi: 10.1210/er.2014-1045

11. Emera D, Romero R, Wagner G. The evolution of menstruation: a new model for genetic assimilation: explaining molecular origins of maternal responses to fetal invasiveness. Bioessays. (2011) 34:26-35. doi: 10.1002/bies.201100099

12. Bellofiore N, Evans J. Monkeys, mice and menses: the bloody anomaly of the spiny mouse. $J$ Assist Reprod Genet. (2019) 36:811-7. doi: 10.1007/s10815-018-1 
13. Bellofiore $\mathrm{N}$, Rana S, Dickinson $\mathrm{H}$, Temple-Smith $\mathrm{P}$, Evans J. Characterization of human-like menstruation in the spiny mouse: comparative studies with the human and induced mouse model. Hum Reprod. (2018) 33:1715-26. doi: 10.1093/humrep/dey247

14. Cox KE, Sharpe-Timms KL, Kamiya N, Saraf M, Donnelly KM, Fazleabas AT. Differential regulation of stromelysin-1 (matrix metalloproteinase-3) and matrilysin (matrix metalloproteinase-7) in baboon endometrium. J Soc Gynecol Investig. (2000) 7:242-8. doi: 10.1016/S1071-5576(00)00062-9

15. Rudolf-Owen LA, Slayden OD, Matrisian LM, Brenner RM. Matrix metalloproteinase expression in Macaca mulatta endometrium: evidence for zone-specific regulatory tissue gradients. Biol Reproduct. (1998) 59:134959. doi: 10.1095/biolreprod59.6.1349

16. Brenner RM, Slayden OD. Molecular and functional aspects of menstruation in the macaque. Rev Endocr Metab Disord. (2012) 13:309-18. doi: 10.1007/s11154-012-9225-5

17. Brenner RM, Nayak NR, Slayden OD, Critchley HO, Kelly RW. Premenstrual and menstrual changes in the macaque and human endometrium: relevance to endometriosis. Ann N Y Acad Sci. (2002) 955:6074. doi: 10.1111/j.1749-6632.2002.tb02766.x

18. Markee JE, Menstruation in intraocular endometrial transplants in the Rhesus monkey. Am J Obstet Gynecol. (1978) 131:5589. doi: 10.1016/0002-9378(78)90119-9

19. Brenner RM, Rudolph L, Matrisian L, Slayden OD. Non-human primate models; artificial menstrual cycles, endometrial matrix metalloproteinases and s.c. endometrial grafts. Hum Reprod. (1996) 11:150-64. doi: 10.1093/humrep/11.suppl_2.150

20. Nayak NR, Brenner RM. Vascular proliferation and vascular endothelial growth factor expression in the rhesus macaque endometrium. J Clin Endocrinol Metab. (2002) 87:1845-55. doi: 10.1210/jcem.87.4.8413

21. Nayak NR, Critchley HO, Slayden OD, Menrad A, Chwalisz K, Baird DT, et al. Progesterone withdrawal up-regulates vascular endothelial growth factor receptor type 2 in the superficial zone stroma of the human and macaque endometrium: potential relevance to menstruation. J Clin Endocrinol Metab. (2000) 85:3442-52. doi: 10.1210/jcem.85.9.6769

22. Saunders PTK, Horne AW. Endometriosis: Etiology, pathobiology, therapeutic prospects. Cell. (2021) 184:280724. doi: 10.1016/j.cell.2021.04.041

23. Cousins FL, Kirkwood PM, Saunders PT, Gibson DA. Evidence for a dynamic role for mononuclear phagocytes during endometrial repair and remodelling. Sci Rep. (2016) 6:36748. doi: 10.1038/srep36748

24. Winuthayanon W, Hewitt SC, Orvis GD, Behringer RR, Korach KS. Uterine epithelial estrogen receptor $\{$ alpha $\}$ is dispensable for proliferation but essential for complete biological and biochemical responses. Proc Natl Acad Sci U S A. (2010) 107:19272-7. doi: 10.1073/pnas.1013226107

25. Henderson NC, Arnold TD, Katamura Y, Giacomini MM, Rodriguez JD, McCarty JH, et al. Targeting of alphav integrin identifies a core molecular pathway that regulates fibrosis in several organs. Nat Med. (2013) 19:161724. doi: $10.1038 / \mathrm{nm} .3282$

26. Kirkwood PM, Gibson DA, Smith JR, Wilson-Kanamori JR, Kelepouri $O$, Esnal-Zufiaurre A, et al. Single-cell RNA sequencing redefines the mesenchymal cell landscape of mouse endometrium. FASEB J. (2021) 35:e21285. doi: 10.1096/fj.202002123R

27. Winuthayanon W, Lierz SL, Delarosa KC, Sampels SR, Donoghue LJ, Hewitt SC, et al. Juxtacrine activity of estrogen receptor alpha in uterine stromal cells is necessary for estrogen-induced epithelial cell proliferation. Scientific reports. (2017) 7:8377. doi: 10.1038/s41598-017-07728-1

28. Conneely OM, Mulac-Jericevic B, DeMayo F, Lydon JP, O’Malley BW. Reproductive functions of progesterone receptors. Recent Prog Horm Res. (2002) 57:339-55. doi: 10.1210/rp.57.1.339

29. Finn CA, Pope M. Vascular and cellular changes in the decidualized endometrium of the ovariectomized mouse following cessation of hormone treatment: a possible model for menstruation. J Endocrinol. (1984) 100:295300. doi: 10.1677/joe.0.1000295

30. Fan X, Krieg S, Kuo CJ, Wiegand SJ, Rabinovitch M, Druzin ML, et al. VEGF blockade inhibits angiogenesis and reepithelialization of endometrium. FASEB J. (2008) 22:3571-80. doi: 10.1096/fj.08-111401

31. Finn CA, Pope M. Control of leucocyte infiltration into the decidualized mouse uterus. J Endocrinol. (1986) 110:93-6. doi: 10.1677/joe.0.1100093
32. Brasted M, White CA, Kennedy TG, Salamonsen LA. Mimicking the events of menstruation in the murine uterus. Biol Reprod. (2003) 69:1273-80. doi: 10.1095/biolreprod.103. 016550

33. Wang Q, Xu X, He B, Li Y, Chen X, Wang J, et al. critical period of progesterone withdrawal precedes endometrial breakdown and shedding in mouse menstrual-like model. Hum Reprod. (2013) 28:16708. doi: 10.1093/humrep/det052

34. Cousins FL, Murray AA, Scanlon JP, Saunders PT. Hypoxyprobe reveals dynamic spatial and temporal changes in hypoxia in a mouse model of endometrial breakdown and repair. BMC Res Notes. (2016) 9:30. doi: 10.1186/s13104-016-1842-8

35. Menning A, Walter A, Rudolph M, Gashaw I, Fritzemeier KH, Roese L. Granulocytes and vascularization regulate uterine bleeding and tissue remodeling in a mouse menstruation model. PLOS ONE. (2012) 7:e41800. doi: 10.1371/journal.pone.0041800

36. Peterse D, Clercq K, Goossens C, Binda MM, F OD, Saunders P, et al. Optimization of endometrial decidualization in the menstruating mouse model for preclinical endometriosis research. Reprod Sci. (2018) 25:157788. doi: 10.1177/1933719118756744

37. Greaves E, Cousins FL, Murray A, Esnal-Zufiaurre A, Fassbender A, Horne AW, et al. A novel mouse model of endometriosis mimics human phenotype and reveals insights into the inflammatory contribution of shed endometrium. Am J Pathol. (2014) 184:1930-9. doi: 10.1016/j.ajpath.2014.03.011

38. Fan X, Krieg S, Hwang JY, Dhal S, Kuo CJ, Lasley BL, et al. Dynamic regulation of Wnt7a expression in the primate endometrium: implications for postmenstrual regeneration and secretory transformation. Endocrinology. (2012) 153:1063-9. doi: 10.1210/en.2011-1826

39. Rudolph M, Döcke WD, Müller A, Menning A, Röse L, Zollner TM, et al. Induction of Overt menstruation in intact mice. PLoS ONE. (2012) 7:e32922. doi: 10.1371/journal.pone.0032922

40. Wang SF, Chen XH, He B, Yin DD, Gao HJ, Zhao HQ, et al. Acute restraint stress triggers progesterone withdrawal and endometrial breakdown and shedding through corticosterone stimulation in mouse menstrual-like model. Reproduction. (2019) 157:149-61. doi: 10.1530/REP-18-0163

41. Kaitu'u-Lino TJ, Morison NB, Salamonsen LA. Estrogen is not essential for full endometrial restoration after breakdown: lessons from a mouse model. Endocrinology. (2007) 148:5105-11. doi: 10.1210/en.2007-0716

42. Marshall E, Lowrey J, Macpherson S, Maybin JA, Collins F, Critchley HO, et al. In silico analysis identifies a novel role for androgens in the regulation of human endometrial apoptosis. J Clin Endocrinol Metab. (2011) 96:E174655. doi: 10.1210/jc.2011-0272

43. Gibson DA, Simitsidellis I, Cousins FL, Critchley HO, Saunders PT. Intracrine Androgens Enhance Decidualization and Modulate Expression of Human Endometrial Receptivity Genes. Scientific reports. (2016) 6:19970. doi: 10.1038/srep19970

44. Cousins FL, Kirkwood PM, Murray AA, Collins F, Gibson DA, Saunders PT. Androgens regulate scarless repair of the endometrial "wound" in a mouse model of menstruation. FASEB J. (2016) 30:2802-11. doi: 10.1096/fj.201600078R

45. Hart R, Doherty DA. The potential implications of a PCOS diagnosis on a woman's long-term health using data linkage. $J$ Clin Endocrinol Metab. (2015) 100:911-9. doi: 10.1210/jc.20143886

46. Maybin JA, Hirani N, Brown P, Jabbour HN, Critchley HO. The regulation of vascular endothelial growth factor by hypoxia and prostaglandin $F(2)$ alpha during human endometrial repair. J Clin Endocrinol Metab. (2011) 96:247583. doi: $10.1210 /$ jc.2010-2971

47. Critchley HO, Osei J, Henderson TA, Boswell L, Sales KJ, Jabbour HN, et al. Hypoxia-inducible factor-1alpha expression in human endometrium and its regulation by prostaglandin E-series prostanoid receptor 2 (EP2). Endocrinology. (2006) 147:744-53. doi: 10.1210/en.2005-1153

48. Semenza GL, Hypoxia-inducible factor 1: master regulator of O2 homeostasis. Curr Opin Genet Dev. (1998) 8:58894. doi: 10.1016/S0959-437X(98)80016-6

49. Semenza GL. HIF-1, O(2), and the 3 PHDs: how animal cells signal hypoxia to the nucleus. Cell. (2001) 107:1-3. doi: 10.1016/S0092-8674(01)00518-9 
50. Maybin JA, Hirani N, Jabbour HN, Critchley HO. Novel roles for hypoxia and prostaglandin E2 in the regulation of IL-8 during endometrial repair. Am J Pathol. (2011) 178:1245-56. doi: 10.1016/j.ajpath.2010.11.070

51. Coudyzer P, Lemoine P, Jordan BF, Gallez B, Galant C, Nisolle M, et al. Hypoxia is not required for human endometrial breakdown or repair in a xenograft model of menstruation. FASEB J. (2013) 27:37119. doi: 10.1096/fj.13-232074

52. Maybin JA, Murray AA, Saunders PTK, Hirani N, Carmeliet P, Critchley HOD. Hypoxia and hypoxia inducible factor-1alpha are required for normal endometrial repair during menstruation. Nature Communicat. (2018) 9:295. doi: 10.1038/s41467-017-02375-6

53. Jabbour HN, Kelly RW, Fraser HM, Critchley HO. Endocrine regulation of menstruation. Endocr Rev. (2006) 27:17-46. doi: 10.1210/er.2004-0021

54. Evans J, Salamonsen LA. Inflammation, leukocytes and menstruation. Rev Endocr Metab Disord. (2012) 13:277-88. doi: 10.1007/s11154-012-9223-7

55. Jones RL, Hannan NJ, Kaitu'u TJ, Zhang J, Salamonsen LA. Identification of chemokines important for leukocyte recruitment to the human endometrium at the times of embryo implantation and menstruation. J Clin Endocrinol Metab. (2004) 89:6155-67. doi: 10.1210/jc.2004-0507

56. Armstrong GM, Maybin JA, Murray AA, Nicol M, Walker C, Saunders PTK, et al. Endometrial apoptosis and neutrophil infiltration during menstruation exhibits spatial and temporal dynamics that are recapitulated in a mouse model. Sci Rep. (2017) 7:17416. doi: 10.1038/s41598-017-17565-x

57. Thiruchelvam U, Dransfield I, Saunders PT, Critchley HO. The importance of the macrophage within the human endometrium. J Leukoc Biol. (2013) 93:217-25. doi: 10.1189/jlb.0712327

58. Qian LW, Fourcaudot AB, Yamane $K$, You T, Chan RK, Leung KP. Exacerbated and prolonged inflammation impairs wound healing and increases scarring. Wound Repair Regen. (2016) 24:26-34. doi: 10.1111/wrr.12381

59. Kaitu'u-Lino TJ, Morison NB, Salamonsen LA. Neutrophil depletion retards endometrial repair in a mouse model. Cell Tissue Res. (2007) 328:197206. doi: 10.1007/s00441-006-0358-2

60. Sasmono RT, Ehrnsperger A, Cronau SL, Ravasi T, Kandane R, Hickey $\mathrm{MJ}$, et al. Mouse neutrophilic granulocytes express mRNA encoding the macrophage colony-stimulating factor receptor (CSF-1R) as well as many other macrophage-specific transcripts and can transdifferentiate into macrophages in vitro in response to CSF-1. J Leukoc Biol. (2007) 82:11123. doi: $10.1189 / \mathrm{jlb} .1206713$

61. Wang W, Vilella F, Alama P, Moreno I, Mignardi M, Isakova A, et al. Singlecell transcriptomic atlas of the human endometrium during the menstrual cycle. Nat Med. (2020) 26:1644-53. doi: 10.1038/s41591-020-1040-z

62. Daley JM, Thomay AA, Connolly MD, Reichner JS, Albina JE. Use of Ly6Gspecific monoclonal antibody to deplete neutrophils in mice. J Leukoc Biol. (2008) 83:64-70. doi: 10.1189/jlb.0407247

63. Xu X, Chen X, Li Y, Cao H, Shi C, Guan S, et al. Cyclooxygenase-2 regulated by the nuclear factor-kappaB pathway plays an important role in endometrial breakdown in a female mouse menstrual-like model. Endocrinology. (2013) 154:2900-11. doi: 10.1210/en.2012-1993

64. Henriet P, Cornet PB, Lemoine P, Galant C, Singer CF, Courtoy PJ, et al. Circulating ovarian steroids and endometrial matrix metalloproteinases (MMPs). Ann N Y Acad Sci. (2002) 955:119-38. doi: 10.1111/j.1749-6632.2002.tb02773.x

65. Gaide Chevronnay HP, Galant C, Lemoine P, Courtoy PJ, Marbaix E, Henriet P. Spatiotemporal coupling of focal extracellular matrix degradation and reconstruction in the menstrual human endometrium. Endocrinology. (2009) 150:5094-105. doi: 10.1210/en.2009-0750

66. Kaitu'u TJ, Shen J, Zhang J, Morison NB, Salamonsen LA. Matrix metalloproteinases in endometrial breakdown and repair: functional significance in a mouse model. Biol Reprod. (2005) 73:672-80. doi: 10.1095/biolreprod.105.042473

67. Evans J, Kaitu'u-Lino T, Salamonsen LA. Extracellular matrix dynamics in scar-free endometrial repair: perspectives from mouse in vivo and human in vitro studies. Biol Reprod. (2011) 85:511-23. doi: 10.1095/biolreprod.111.090993

68. Kaitu'u-Lino TJ, Phillips DJ, Morison NB, Salamonsen LA. A new role for activin in endometrial repair after menses. Endocrinology. (2009) 150:190411. doi: 10.1210/en.2008-0738
69. Kaitu'u-Lino TJ, Ye L, Gargett CE. Reepithelialization of the uterine surface arises from endometrial glands: evidence from a functional mouse model of breakdown and repair. Endocrinology. (2010) 151:338695. doi: 10.1210/en.2009-1334

70. Kaitu'u-Lino TJ, Ye L, Salamonsen LA, Girling JE, Gargett CE. Identification of label-retaining perivascular cells in a mouse model of endometrial decidualization, breakdown, and repair. Biol Reprod. (2012) 86:184. doi: 10.1095/biolreprod.112.099309

71. Huang CC, Orvis GD, Wang Y, Behringer RR. Stromal-to-epithelial transition during postpartum endometrial regeneration. PLoS ONE. (2012) 7:e44285. doi: 10.1371/journal.pone.0044285

72. Patterson AL, Zhang L, Arango NA, Teixeira J, Pru JK. Mesenchymalto-epithelial transition contributes to endometrial regeneration following natural and artificial decidualization. Stem Cells Dev. (2013) 22:96474. doi: $10.1089 / \mathrm{scd} .2012 .0435$

73. Ghosh A, Syed SM, Kumar M, Carpenter TJ, Teixeira JM, Houairia N, et al. In vivo cell fate tracing provides no evidence for mesenchymal to epithelial transition in adult fallopian tube and uterus. Cell Rep. (2020) 31:107631. doi: 10.1016/j.celrep.2020.107631

74. Cousins FL, Pandoy R, Jin S, Gargett CE. The elusive endometrial epithelial stem/progenitor cells. Front Cell Dev Biol. (2021) 9:640319. doi: 10.3389/fcell.2021.640319

75. Schwab KE, Gargett CE. Co-expression of two perivascular cell markers isolates mesenchymal stem-like cells from human endometrium. Hum Reprod. (2007) 22:2903-11. doi: 10.1093/humrep/dem265

76. Wyatt KA, Filby CE, Davies-Tuck ML, Suke SG, Evans J, Gargett CE. Menstrual fluid endometrial stem/progenitor cell and supernatant protein content: cyclical variation and indicative range. Hum Reprod. (2021) 36:2215-29. doi: 10.1093/humrep/deab156

77. Gargett CE, Gurung S, Darzi S, Werkmeister JA, Mukherjee S. Tissue engineering approaches for treating pelvic organ prolapse using a novel source of stem/stromal cells and new materials. Curr Opin Urol. (2019) 29:450-7. doi: 10.1097/MOU.0000000000000634

78. Li Z, Bian X, Ma Y, Yang Q, Jia W, Liu J, et al. Uterine scarring leads to adverse pregnant consequences by impairing the endometrium response to steroids. Endocrinology 161. (2020). doi: 10.1210/endocr/bqaa174

79. Freedman MF, Schlaff WD. Avoiding Asherman's syndrome: refining our approach to uterine evacuation. Fertil Steril. (2021) 116:9612. doi: $10.1016 /$ j.fertnstert.2021.06.037

80. Alawadhi F, Du H, Cakmak H, Taylor HS. Bone MarrowDerived Stem Cell (BMDSC) transplantation improves fertility in a murine model of Asherman's syndrome. PLoS ONE. (2014) 9:e96662. doi: 10.1371/journal.pone.0096662

81. Jun SM, Park M, Lee JY, Jung S, Lee JE, Shim SH, et al. Single cell-derived clonally expanded mesenchymal progenitor cells from somatic cell nuclear transfer-derived pluripotent stem cells ameliorate the endometrial function in the uterus of a murine model with Asherman's syndrome. Cell Prolif. (2019) 52:e12597. doi: 10.1111/cpr.12597

82. Gargett CE, Schwab KE, Deane JA. Endometrial stem/progenitor cells: the first 10 years. Hum Reprod Update. (2016) 22:13763. doi: 10.1093/humupd/dmv051

83. Park M, Hong SH, Park SH, Kim YS, Yang SC, Kim HR, et al. Perivascular stem cell-derived cyclophilin A improves uterine environment with asherman's syndrome via HIFlalpha-dependent angiogenesis. Mol Ther. (2020) 28:1818-32. doi: 10.1016/j.ymthe.2020.05.015

84. Salama NM, Zaghlol SS, Mohamed HH, Kamar SS. Suppression of the inflammation and fibrosis in Asherman syndrome rat model by mesenchymal stem cells: histological and immunohistochemical studies. Folia Histochem Cytobiol. (2020) 58:208-18. doi: 10.5603/FHC.a2020.0024

85. Gao M, Yu Z, Yao D, Qian Y, Wang Q, Jia R. Mesenchymal stem cells therapy: A promising method for the treatment of uterine scars and premature ovarian failure. Tissue Cell. (2021) 74:101676. doi: 10.1016/j.tice.2021.101676

86. Santamaria X, Isaacson K, Simon C. Asherman's Syndrome: it may not be all our fault. Hum Reprod. (2018) 33:1374-80. doi: 10.1093/humrep/dey232

87. Campana L, Esser H, Huch M, Forbes S. Liver regeneration and inflammation: from fundamental science to clinical applications. Nature reviews. Molecular Cell Biology. (2021) 22:608-24. doi: 10.1038/s41580-021-00373-7 
88. Liu D, Wang J, Zhao G, Jiang P, Song M, Ding H, et al. CSF1-associated decrease in endometrial macrophages may contribute to Asherman's syndrome. Am J Reprod Immunol. (2020) 83:e13191. doi: 10.1111/aji. 13191

89. Forster R, Sarginson A, Velichkova A, Hogg C, Dorning A, Horne AW, et al. Macrophage-derived insulin-like growth factor-1 is a key neurotrophic and nerve-sensitizing factor in pain associated with endometriosis. FASEB J. (2019) 33:11210-22. doi: 10.1096/fj.201900797R

90. Henderson NC, Rieder F, Wynn TA. Fibrosis: from mechanisms to medicines. Nature. (2020) 587:555-66. doi: 10.1038/s41586-0202938-9

91. Queckborner S, von Grothusen C, Boggavarapu NR, Francis RM, Davies LC, Gemzell-Danielsson K. Stromal heterogeneity in the human proliferative endometrium-A single-cell RNA sequencing study. J Pers Med 11. (2021). doi: 10.3390/jpm11060448

92. Jiang D, Correa-Gallegos D, Christ S, Stefanska A, Liu J, Ramesh P, et al. Two succeeding fibroblastic lineages drive dermal development and the transition from regeneration to scarring. Nat Cell Biol. (2018) 20:42231. doi: 10.1038/s41556-018-0073-8

93. Yin JL, Wu Y, Yuan ZW, Gao XH, Chen HD. Advances in scarless foetal wound healing and prospects for scar reduction in adults. Cell Prolif. (2020) 53:e12916. doi: 10.1111/cpr.12916

94. Glim JE, van Egmond M, Niessen FB, Everts V, Beelen RH. Detrimental dermal wound healing: what can we learn from the oral mucosa? Wound Repair Regen. (2013) 21:648-60. doi: 10.1111/wrr. 12072

95. Iglesias-Bartolome $\mathrm{R}$, Uchiyama A, Molinolo AA, Abusleme L, Brooks SR, Callejas-Valera JL, et al. Transcriptional signature primes human oral mucosa for rapid wound healing. Sci Transl Med. (2018) 10. doi: $10.1126 /$ scitranslmed.aap 8798

96. Pereira D, Sequeira I. A scarless healing tale: comparing homeostasis and wound healing of oral mucosa with skin and oesophagus. Front Cell Dev Biol. (2021) 9:682143. doi: 10.3389/fcell.2021.682143
97. Sezgin B, Tatar S, Karahuseyinoglu S, Sahin GN, Ergun Y, Meric G, et al. The effects of oral mucosa-derived heterotopic fibroblasts on cutaneous wound healing. J Plast Reconstr Aesthet Surg. (2021) 74:27518. doi: 10.1016/j.bjps.2021.02.011

98. Szpaderska AM, Zuckerman JD, DiPietro LA. Differential injury responses in oral mucosal and cutaneous wounds. J Dent Res. (2003) 82:6216. doi: 10.1177/154405910308200810

99. Brant JO, Yoon JH, Polvadore T, Barbazuk WB, Maden M. Cellular events during scar-free skin regeneration in the spiny mouse, Acomys. Wound Repair Regen. (2016) 24:75-88. doi: 10.1111/wrr.12385

100. Peake MA, Caley M, Giles PJ, Wall I, Enoch S, Davies LC, et al. Stephens, Identification of a transcriptional signature for the wound healing continuum. Wound Repair Regen. (2014) 22:399-405. doi: 10.1111/wrr.12170

Conflict of Interest: The authors declare that the research was conducted in the absence of any commercial or financial relationships that could be construed as a potential conflict of interest.

Publisher's Note: All claims expressed in this article are solely those of the authors and do not necessarily represent those of their affiliated organizations, or those of the publisher, the editors and the reviewers. Any product that may be evaluated in this article, or claim that may be made by its manufacturer, is not guaranteed or endorsed by the publisher.

Copyright (c) 2022 Kirkwood, Shaw and Saunders. This is an open-access article distributed under the terms of the Creative Commons Attribution License (CC BY). The use, distribution or reproduction in other forums is permitted, provided the original author(s) and the copyright owner(s) are credited and that the original publication in this journal is cited, in accordance with accepted academic practice. No use, distribution or reproduction is permitted which does not comply with these terms. 